International Journal of Electrical Engineering and Technology (IJEET)

Volume 11, Issue 4, June 2020, pp. 456-468, Article ID: IJEET_11_04_050

Available online at https://iaeme.com/Home/issue/IJEET? Volume $=11 \&$ Issue $=4$

ISSN Print: 0976-6545 and ISSN Online: 0976-6553

DOI: https://doi.org/10.34218/IJEET.11.4.2020.050

\title{
INTRODUCING DYNAMIC FEATURE IN MAXIMUM POWER POINT TRACKING ALGORITHM FOR PV SYSTEM
}

\author{
Md. Ehtesham \\ Electrical \& Electronics Department, Maulana Azad National Urdu University, India
}

\begin{abstract}
Photovoltaic (PV) power has become the most attractive choice among various renewable resources. However, one major challenge associated with PV interfacing is its intermittent output characteristic which varies dramatically with the operating conditions. Thus designing an effective maximum power point tracking (MPPT) algorithm is a key aspect for optimizing PV system performance. Numerous MPPT algorithms have been proposed earlier having their own specific advantages. However, these are found to have two major limitations which have to be essentially addressed. Firstly, they become ineffective in the dynamic conditions where there is rapid change in environmental parameters like insolation and temperature. Secondly, they fail to discriminate between global and local peaks under partial shading conditions. Therefore, to achieve a reliable and efficient system operation, this paper presents an optimized algorithm which enhances the model-based (MB) tracking capability so as to overcome both the above deficiencies. On the basis of modified governing equations and incorporating the precised estimation of parameters, it predetermines the MPP analytically. First simulated results are obtained where it is tested for dynamic variations of all the three parameters. Then the experimental validation is carried out on a $2 \mathrm{KW}$ installed panel where real time data is recorded through CR1000 data logger and environmental parameters are sensed with elements like pyranometer, humidity sensor, etc. Numerous experimental results are analyzed for tracked MPP in the dynamic conditions, which are then summarized in tabular forms. These are finally plotted and compared with simulated results to illustrate the effectiveness of proposed MB algorithm.
\end{abstract}

Key words: Dynamic conditions, maximum power point tracking, model-based algorithm, partial shading, photovoltaic.

Cite this Article: Md. Ehtesham, Introducing Dynamic Feature in Maximum Power Point Tracking Algorithm for PV System, International Journal of Electrical Engineering and Technology (IJEET), 11(4), 2020, pp. 460-472.

https://iaeme.com/Home/issue/IJEET?Volume=11\&Issue $=4$ 


\section{INTRODUCTION}

Over the last few decades there has been a tremendous trend of exploiting the renewable sources of energy on account of various factors like climatic concern, depletion of conventional energy reservoirs, global warming, etc. Among all the renewable sources, Photovoltaic (PV) promises to be the most attractive solution as a result of latest advancements in semiconductor materials and power electronic converters. Despite of several advantages [1] that PV system offers, one major challenge for the large scale interfacing of PV power is its non-linear output characteristics which vary with the ambient operating conditions [2]. The situation gets further worsened for dynamic conditions [3] where there is rapid variation in the environmental conditions. Thus it demands for comprehensive assessment of characteristics in terms of dynamic behaviour and to design advance tracking scheme so that PV panel is essentially made to operate at maximum power point (MPP) in order to optimize the system performance.

There have been a large number of MPPT algorithms applied by the researchers [4 - 7]. These techniques differ from one another from various functional aspects and have their individual pros and cons. Rigorous review of MPPT algorithms reveals that these can be broadly divided into (a) conventional and (b) soft computing techniques. As far as conventional MPPT techniques are concerned, it is found that perturb and observe (P\&O) [8] and incremental conductance (IC) [9] are preferred most. But there is one major drawback associated with P\&O that as the perturbation rate increases it also leads to higher oscillations in system around MPP and thus selection of proper step-size poses a challenge. Authors in [10] propose an alternative approach with variation in step-size so as to mitigate this drawback. Here oscillations at steady state have been reduced significantly and higher system efficiency has been achieved. However, it shows capability of tracking MPP effectively only while operating conditions are uniform. Performance is found to be sluggish and convergence is poor under partial shading. Similarly, IC technique applied by authors in [11], analyzes MPPT capability under system transients with greater oscillating frequencies. The proposed technique is simple and efficient but the drawback is that it is found to be effective in low power applications only without any dynamic change in conditions.

With the evolution in intelligence technique, there have been a number of MPPT algorithms developed in recent years on the basis of soft computing. Among these evolutionary techniques, the likes of fuzzy logic control (FLC) [12], artificial neural network (ANN) [13], genetic algorithm (GA) [14], particle swarm optimization (PSO) [15] are some of the most explored ones. In [16] a FLC based MPPT scheme has been implemented which shows good tracking capability for load variations as well. The biggest merit of FLC based algorithms is their tracking speed and they are found to be best suited option for reduction in settling time. However, FLC suffers from the limitation that once rules have been defined they can hardly be modified and therefore it requires significant training for achieving effective tracking under dynamic conditions. Thus FLC is seldom used alone and preferably it is combined with other tracking algorithms to be incorporated as hybrid technique [17]. But then of course system complexity becomes a major issue. Based on Neuro-Fuzzy algorithm, authors in [18] have implemented an adaptive tracking which considerably improves the conversion efficiency and is found to be applicable under all conditions. But the ANN technique poses the challenge of longer computational time and greater memory requirement which in turn enhances the complexity. Similarly, GA based algorithms which are mainly employed for stochastic searches, also have the same drawback of large memory and training requirement because of high initial population. PSO is particularly well suited for tracking of global maxima under partial shading cases where panels are non-uniformly illuminated. However, initialization of parameter is a challenge in PSO based technique which results into the randomness in initial duty cycle. Another drawback of PSO technique is that with the increase in population size, 
computational difficulty also increases. In context of effectiveness of various tracking schemes it should also be noted here that partial shading phenomenon gives rise to several ill effects causing considerable amount of power loss with danger of panel even getting damaged [19-20]. Therefore, to design a simple and effective algorithm for minimizing the consequences of partial shading continues to be another challenging aspect in the field of MPPT, even though there have been many proposed work.

Thus in view of detailed analysis of MPPT algorithms as discussed above, it is observed that there exists a number of techniques which perform satisfactorily in uniform conditions with steady variations in environmental parameters. However, there are two major and common drawbacks associated with these methods which need to be addressed for efficient and reliable PV system performance. The first is that they fail to respond effectively when there is dynamic change in the environmental conditions. It means that their operating point drifts away from MPP when the conditions are varied rapidly. Secondly, they show incapability to guarantee the successful tracking of global MPP in case of the partial shading or non-uniform solar irradiance. Thus in order to overcome the above deficiencies, here in this work a simplified and enhanced model-based (MB) MPPT algorithm is proposed. It has distinct capability of working effectively both in dynamic conditions with rapid and continuous variations in environmental parameters and under shaded conditions as well. On the basis of mathematical modeling governing equations have been framed and precisely estimated parameters have been employed to avoid heuristic searching of maxima. Thus the proposed MB algorithm ensures reliable tracking in the dynamic working conditions by means of pre-determining MPP analytically.

\section{SYSTEM MODELING FOR PROPOSED MB ALGORITHM}

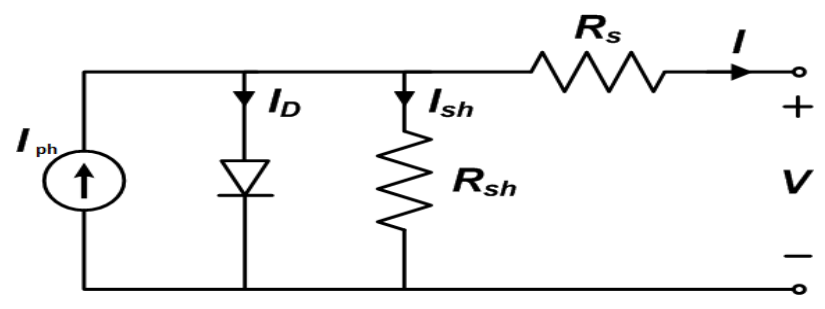

Figure 1 Equivalent single diode PV circuit

There are two main aspects involved in accomplishing model based MPPT algorithm which induces the distinguished tracking feature. First of all it implies the task of accurate modeling of PV panel. Several models for the PV panel have been proposed in literature where single diode and two diode model are found to be most common ones [21, 22]. Single diode model shown in Fig. 1 is found to be the most suitable one, offering simplicity with enough accuracy and hence it has been applied here while modeling the PV circuit. A replacement track is created by the parallel connected diode (bypass diode) which prevents the damaging effects of hotspots. On the basis of equivalent circuit expression for output current can be simply given as equation (1).

$$
\mathrm{I}=\mathrm{I}_{\mathrm{ph}}-\mathrm{I}_{\mathrm{D}}-\mathrm{I}_{\mathrm{sh}}
$$

Now, applying theory of semiconductors modified expression can be given as equation (2).

$$
\mathrm{I}=\mathrm{I}_{\mathrm{ph}}-\mathrm{I}_{\mathrm{o}}\left(\exp \left(\frac{V+R_{S} I}{\alpha V_{t}}\right)-1\right)-\frac{V+R_{S} I}{R_{s h}}
$$

Where, $\mathrm{I}_{\mathrm{o}}$ is the reverse saturation current, $\alpha$ is the ideality factor and $V_{t}$ is the thermal voltage. Here for restricting the panel operation around MPP, characteristic matching is performed by tuning the thermal voltage from time to time with the series resistance $\left(R_{s}\right)$. The relevancy of shunt resistance can be ignored as it hardly impacts the behaviour for MPP region. 
Thus all the factors affecting accuracy of PV model have been taken care and these set a benchmark for governing the PV characteristics under dynamic conditions.

Now the next important aspect while optimizing this tracking algorithm and which is crucial for developing dynamic capability is estimating the parameters with great precision. Generally, panel specifications are declared by the manufacturer (as given in Table I) indicating voltage and current ratings for vertices like open circuit, short circuit and MPP. Thus PV model can be defined utilizing rated values from datasheet for Standard Test Conditions (STC: Insolation S= $1000 \mathrm{~W} / \mathrm{m}^{2}$, Temperature $\mathrm{T}=25^{\circ} \mathrm{C}$ ). But designing the model using specified data may lead to certain inaccuracy due to dispersion of the manufacturing scheme and unused rated values. Thus to obtain a highly precised model, here in MB algorithm all the environmental parameters are measured precisely with the help of pyranometer and humidity sensor as shown in the next section. Then accordingly PV panel parameters are estimated so as to get a highly accurate tuning with environmental conditions. This predictive approach leads to prediction of error in advance to switching signals fed to converter. It utilizes the precised modeling and estimation which enables it to pre-determine the MPP analytically. Therefore, proposed algorithm avoids searching of MPP heuristically which is commonly applied in literature. Consequently, it achieves a significant enhancement in tracking capability under dynamic conditions resulting into high accuracy and efficiency.

Finally for successful implementation of MB algorithm some mathematical operations are carried out which leads to accurate characterization of the PV panel in the region of MPP. Once the operating voltage and current for MPP is obtained then the output power is differentiated and equated to zero as expressed by equation (3) and equation (4). Imposition of these set of equations helps to tune the model and bounds the system to track its maxima under all sort of dynamic conditions.

$$
\begin{gathered}
\mathrm{V}_{m p}=\mathrm{V}_{o c}+\mathrm{V}_{T} \ln \left(1-\frac{\mathrm{I}_{\mathrm{mp}}}{\mathbf{I}_{\mathrm{sc}}}\right)-\mathbf{R}_{s} \mathrm{I}_{m p} \\
\left.\frac{\mathrm{d}(\mathrm{VI})}{\mathrm{dI}}\right|_{\mathrm{I}=\mathrm{I}_{\mathrm{mp}}}=\mathrm{V}_{\mathrm{mp}}+\frac{\mathrm{V}_{\mathrm{T}} \mathrm{I}_{\mathrm{mp}}}{\mathrm{I}_{\mathrm{mp}}-\mathrm{I}_{\mathrm{sc}}}-\mathbf{R}_{\mathrm{s}} \mathrm{I}_{\mathrm{mp}}=\mathbf{0}
\end{gathered}
$$

\section{HARDWARE PLATFORM FOR MB MPPT ANALYSIS}

This section presents the description of hardware setup along with all its components that provided a platform for experimental analysis of MB algorithm. PV panels of $2 \mathrm{KW}$ rating were explored for this work which consists of ten polycrystalline modules, five monocrystalline and five thin film modules each of $100 \mathrm{~W}$ rating. A picture of installed panel is shown by Figure 2 whereas the panel specifications have been summarized in Table 1. As discussed earlier, crux of MB algorithm is the optimum estimation of PV model parameters as a function of their dependency on environmental conditions. Thereby, variations in factors like solar insolation, humidity and wind speed have been tried to be measured with utmost accuracy. Pyranometer has been used here to precisely measure the solar insolation. It is a sensor that measures flux density or global radiation and bears almost a linear relation with the frequency band of total solar radiation. It can also measure the diffuse radiation for which pyranometer is shaded with a disk placed for preventing the direct incidence of beam. Similarly, a humidity sensor has been also used to give the measure of water vapour in the atmosphere. It is related with the temperature in the sense that vapour content of hot air is greater than that of cold air. A picture of installed sensors has been shown in Figure 3. 
Table 1 Specifications of practical $2 \mathrm{KW}$ panels installed

\begin{tabular}{|c|l|l|}
\hline S.No. & \multicolumn{1}{|c|}{ Parameters (per module) } & \multicolumn{1}{|c|}{ Value } \\
\hline 1 & $\mathrm{P}_{\mathrm{mpp}}$ & $100 \mathrm{~W}$ \\
\hline 2 & $\mathrm{~V}_{\mathrm{mpp}}$ & $17.7 \mathrm{~V}$ \\
\hline 3 & $\mathrm{I}_{\mathrm{mpp}}$ & $5.6 \mathrm{~A}$ \\
\hline 4 & $\mathrm{~V}_{\mathrm{oc}}$ & $21.7 \mathrm{~V}$ \\
\hline 5 & $\mathrm{I}_{\mathrm{sc}}$ & $6.2 \mathrm{~A}$ \\
\hline 6 & Tolerance & $2 \%$ \\
\hline
\end{tabular}

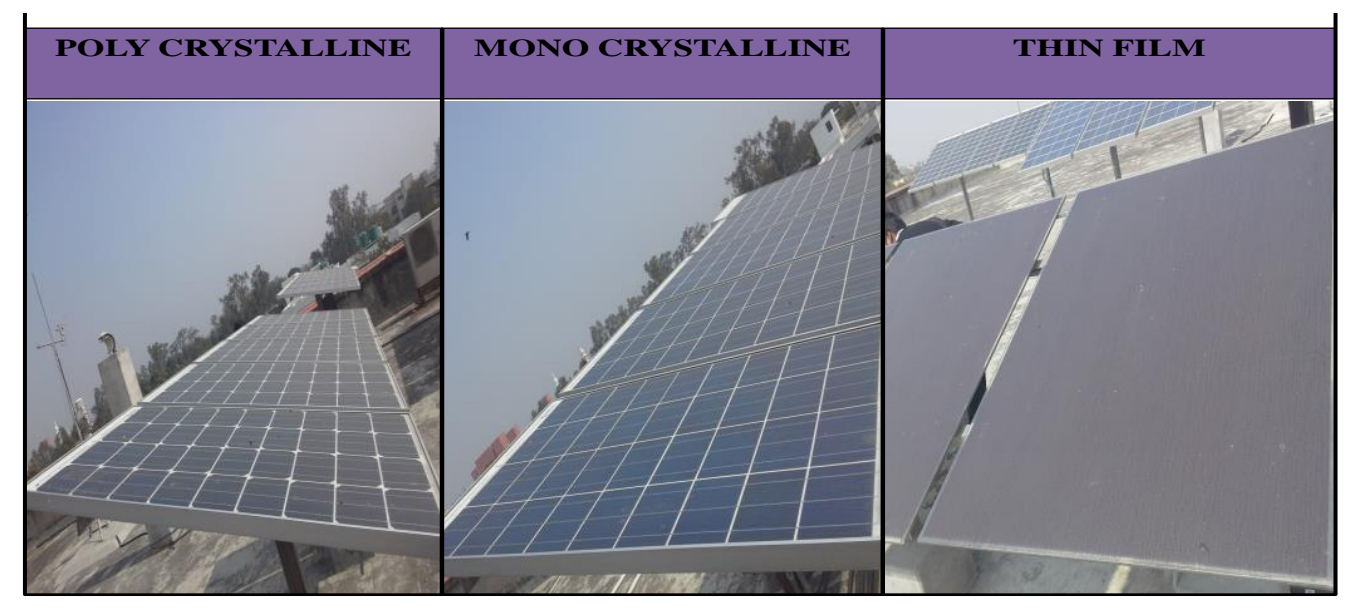

Figure 2 PV panels installed on roof-top
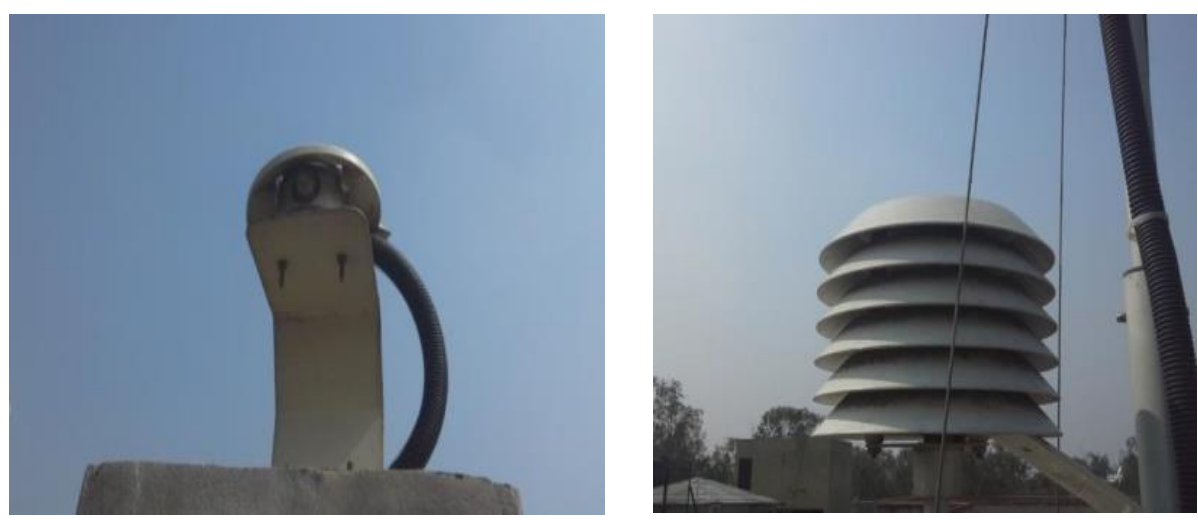

Figure 3 Installed measuring devices (a) Pyranometer (b) Humidity sensor

Further, it has to be noted here that any kind of monitoring scheme utilizing sensor monitoring requires a data collection system. For this purpose a portable CR1000 data logger was installed which keeps recording all the measured values of parameters as well as corresponding variations in panel characteristics. This data logger was synchronised with a display board setup inside the lab and also connected to a computer. Hence the instantaneous values of current, voltage and power were available in the display board whereas a continuous record of the same was stored in the system. Figure 4 shows a picture of data logger and display panel is shown in Figure 5. 


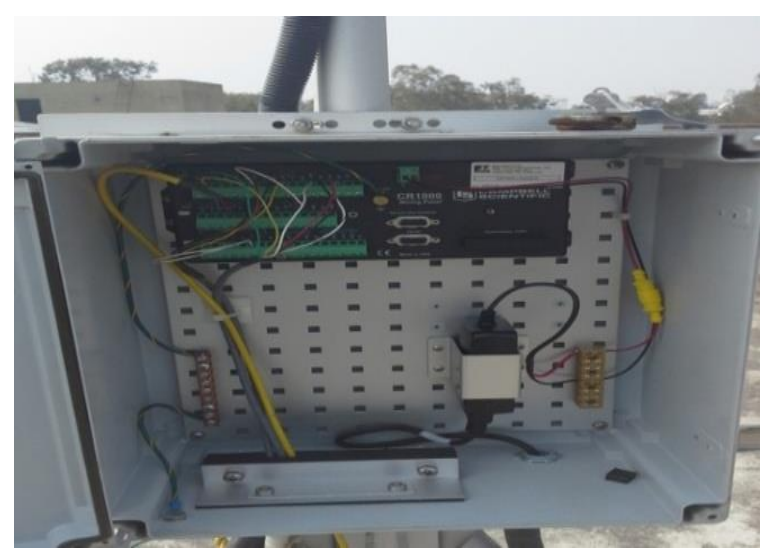

Figure 4 CR 1000 data logger

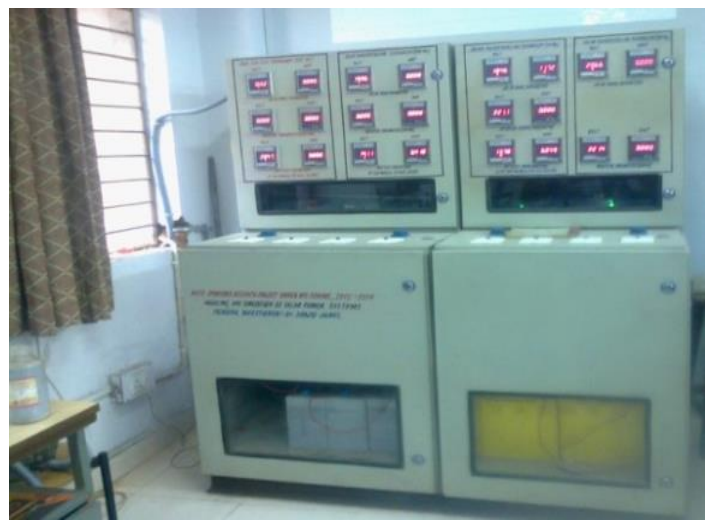

Figure 5 Display board setup

\section{RESULTS AND DISCUSSION}

Having estimated all the parameters precisely with their dependency established on the working conditions, now the detailed analysis of tracking performance is presented in this section. Here the effectiveness of proposed algorithm is evaluated for rapid variations of all sorts of environmental conditions including partial shading over their full practical range. First the MB algorithm is tested in MATLAB/Simulink platform where simulated results of tracked MPP for dynamic insolation, temperature and shading are presented. Then the real time performance is analysed where experimental results have been discussed. Finally for validating the effectiveness of MB technique both the results are plotted and compared.

\subsection{Simulation Results}

Simulink model has been strictly designed on the basis of mathematical equations characterizing the MB algorithm as discussed earlier. First the photocurrent $\left(\mathrm{I}_{\mathrm{ph}}\right)$ is evaluated as a function of solar radiation, then after proper computation of reverse saturation current $\left(\mathrm{I}_{\mathrm{o}}\right)$ and thermal voltage $\left(\mathrm{V}_{\mathrm{t}}\right)$ diode current is obtained as shown by building blocks in Figure 6 . Here it can be seen that diode current has exponential dependency on thermal voltage. Thereafter the summation of diode current and shunt current is subtracted from photocurrent to result into the panel output current as illustrated by the blocks in Figure 7. Thus once the tuned values for current and values are estimated for MPP operation, these are exported to workspace for processing maximum power output as shown in Figure 8.
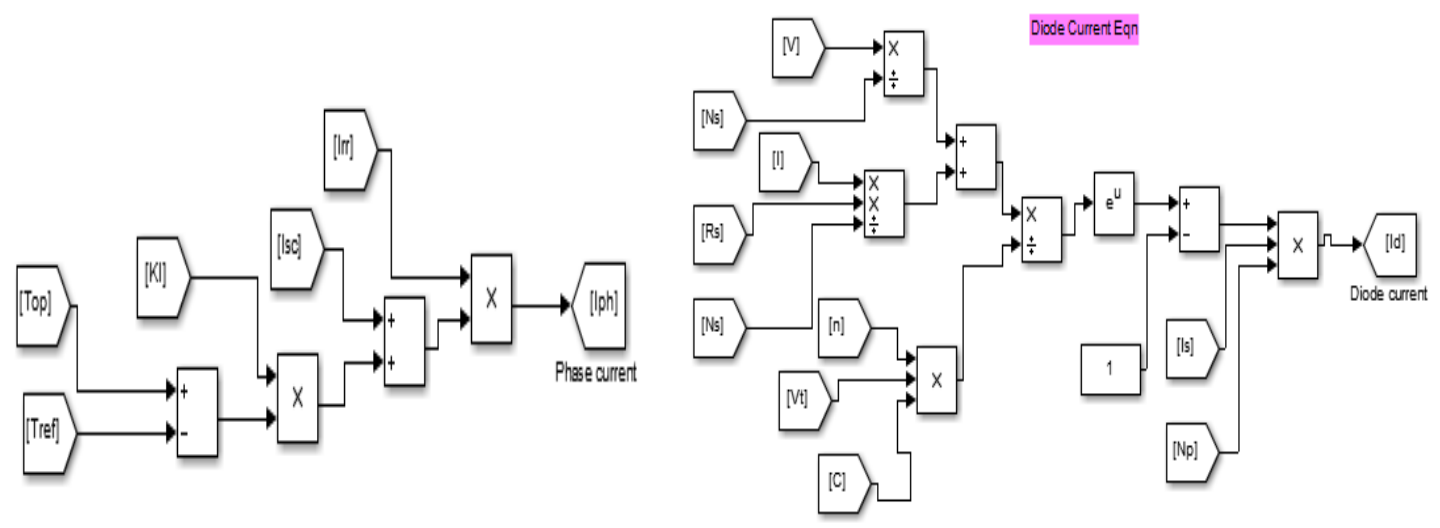

Figure 6 Blocks for simulating (a) Photocurrent (b) Diode current 


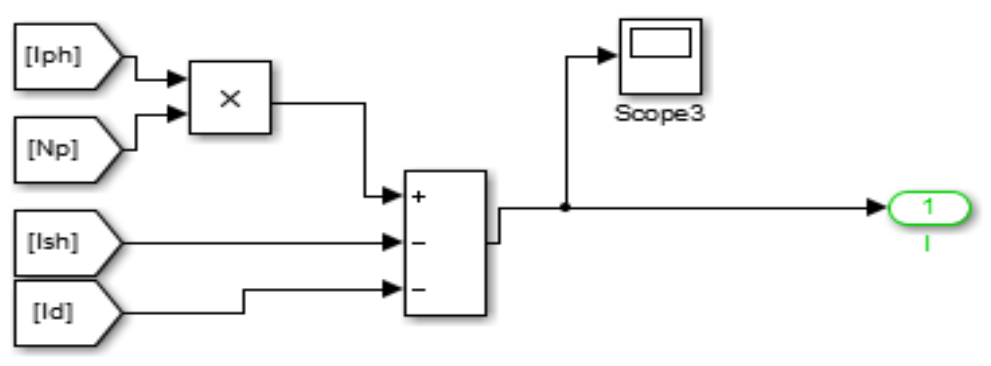

Figure 7 Modeling of Panel output current

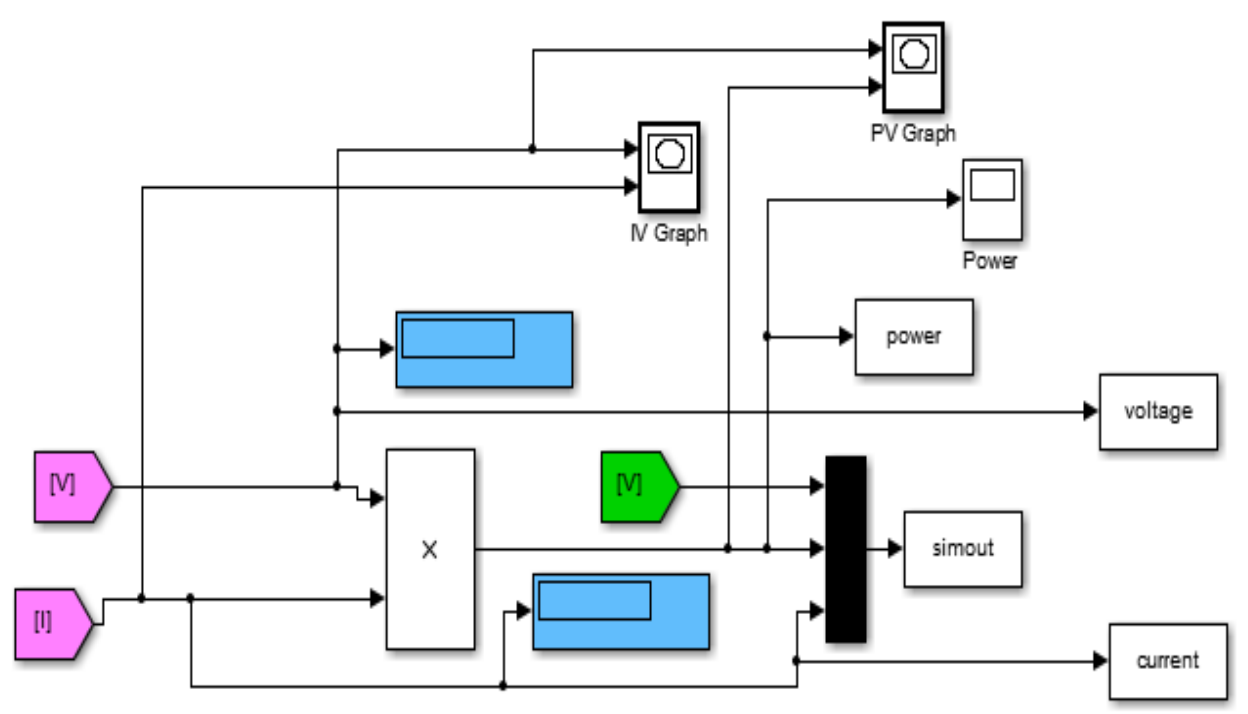

Figure 8 Simulated blocks for estimating power output

Now before going for dynamic variations in operating conditions, first of all the output characteristic is observed at standard test condition (STC). This sets a benchmark for the rest of evaluation and also ratifies higher tracking efficiency of proposed algorithm. Figure 9 shows the PV curve obtained at STC where it is observed that maximum power of $1920 \mathrm{~W}$ is successfully tracked when panel voltage reaches a mark of about $190 \mathrm{~V}$. Thus MB algorithm is not only effective for dynamic conditions but it is also capable of yielding a higher tracking efficiency.

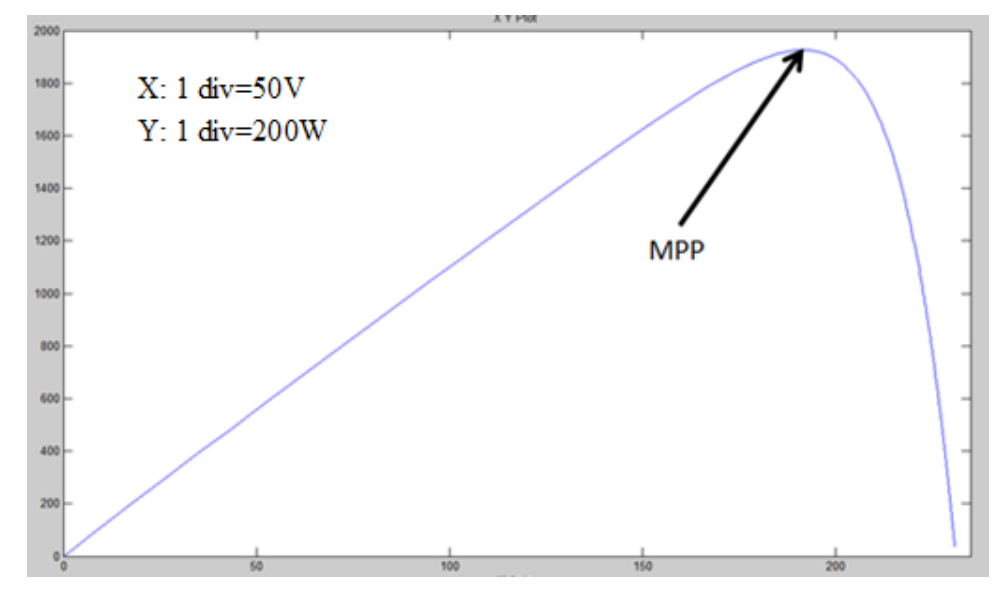

Figure 9 PV characteristic obtained at STC 
Now effectiveness of proposed tracking algorithm is tested by obtaining PV power characteristics under dynamic conditions where different parameters are varied alternately. First the impact of insolation variation over tracking ability is tested where temperature is kept constant at $25{ }^{\circ} \mathrm{C}$ and insolation varies dynamically throughout the scale from $100 \mathrm{~W} / \mathrm{m}^{2}$ to $1000 \mathrm{~W} / \mathrm{m}^{2}$. Thus output characteristics also changes dynamically and correspondingly for each particular characteristic global maxima is tracked effectively. Therefore, numerous PV curves are obtained with successful tracking of MPP for insolation varying dynamically from 100 to 200 to 300 and so on. Since it is impractical to present here all the characteristics and MPP tracked for corresponding insolation, thus only one such characteristic obtained at insolation of $600 \mathrm{~W} / \mathrm{m}^{2}$ is shown here in Figure 10. Next, temperature is varied throughout a scale of $12^{\circ} \mathrm{C}$ to $45^{\circ} \mathrm{C}$ keeping the insolation at a level of $1000 \mathrm{~W} / \mathrm{m}^{2}$. Again numerous PV curves are obtained with successful tracking of MPP for temperature varying dynamically. Figure 11 shows one of the characteristics which is obtained for operating temperature of $15^{\circ} \mathrm{C}$.

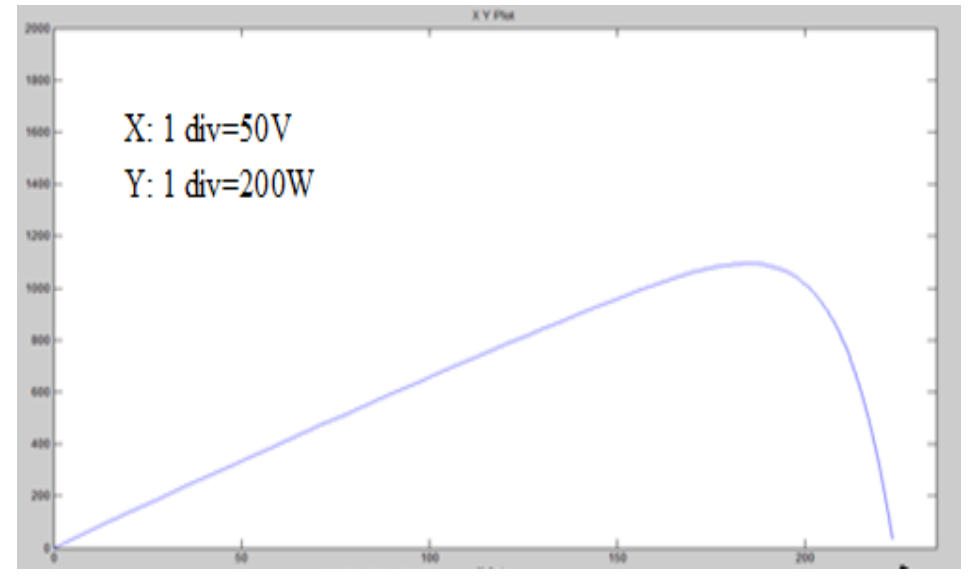

Figure $10 \mathrm{PV}$ characteristic at an insolation of $600 \mathrm{~W} / \mathrm{m}^{2}\left(\mathrm{~T}=25^{\circ} \mathrm{C}\right)$

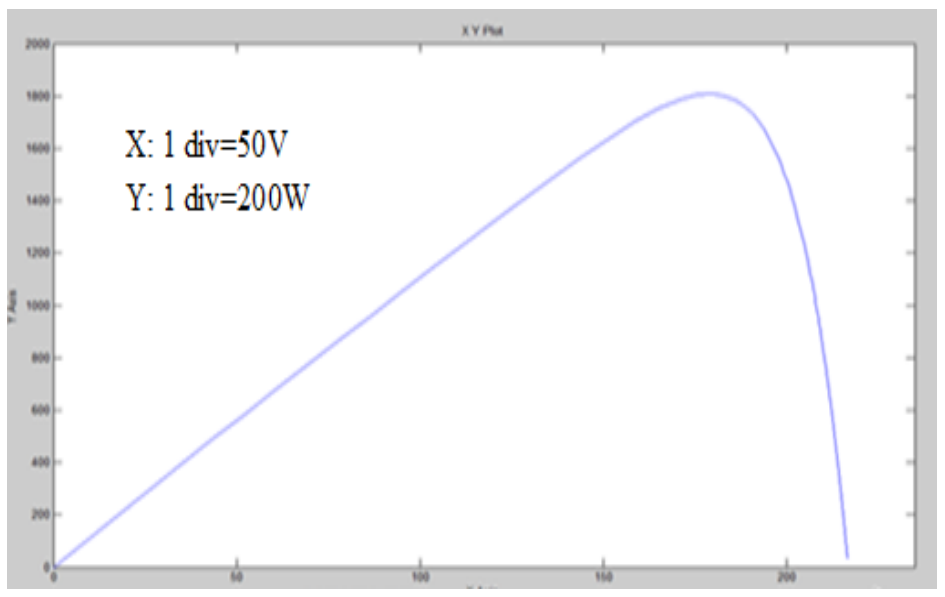

Figure $11 \mathrm{PV}$ characteristic at Temperature of $15^{\circ} \mathrm{C}\left(\mathrm{S}=1000 \mathrm{~W} / \mathrm{m}^{2}\right)$

Finally effectiveness of MB algorithm is tested for dynamically tracking MPP for the shaded panels. As shown in Figure 12 MPP is tracked successfully for dynamic variations in shading percentage in steps of $10 \%$. Interestingly, for shaded conditions the voltage variation is not much significant up to a level $70 \%$ of shading. However, the current varies much significantly with shading. Further, it is observed that panel current becomes negative for a fully shaded case as an impact of reverse saturation. 


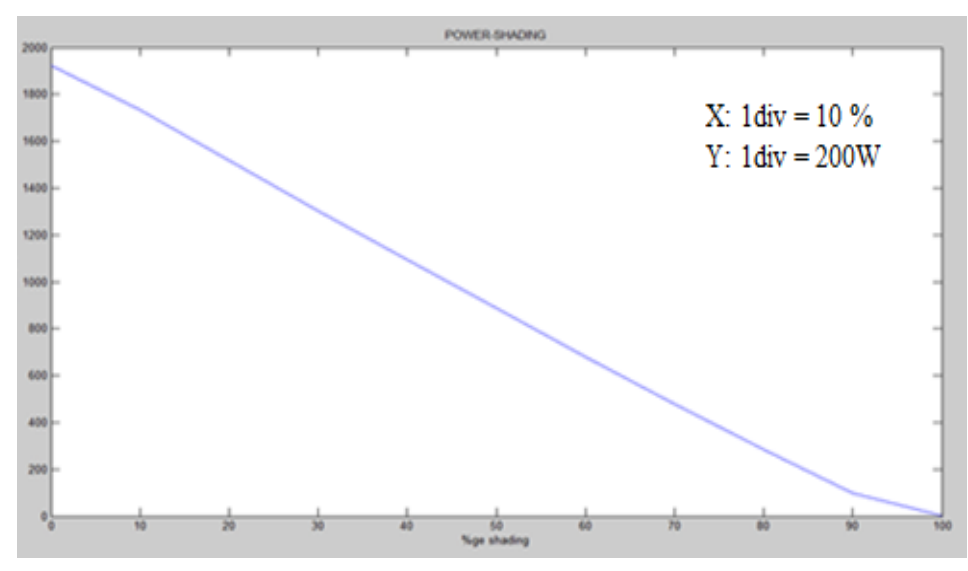

Figure 12 MPP tracked for dynamic $\%$ shading

\subsection{Experimental Analysis}

Results of the simulation work have been extensively verified with that of experimental one for validation of the effectiveness of proposed tracking scheme. As stated in section 3, practical monitoring of dynamic variations was carried out by means of sensors followed by estimation of data. The corresponding estimated values in terms of variations in current, voltage and power at point of tracked maxima have been recorded by data logger. Further, these readings were also tracked continuously in the display panel shown in Figure 5 and stored in computer as well. As done in the case of simulated results, here also we start with first tracking the MPP at STC for which the obtained readings are summarized in Table 2. This is demonstrated by summarization of the experimentally tracked maxima for alternate dynamic conditions where apart from the maximum power output, the corresponding current and voltage readings at MPP have also been specified. Following the sequence as before next investigation has been done for tracking ability under dynamic insolation in between $100 \mathrm{~W} / \mathrm{m}^{2}$ to $1000 \mathrm{~W} / \mathrm{m}^{2}$. Table 3 summarizes the experimental results obtained corresponding to same.

Table 2 Experimental PV characteristic at STC

\begin{tabular}{|c|c|c|}
\hline Voltage (V) & Current (A) & Power $(\mathbf{W})$ \\
\hline 50 & 11.172 & 584.3 \\
\hline 100 & 11.024 & 1124.7 \\
\hline 120 & 10.831 & 1298.3 \\
\hline 140 & 10.373 & 1558.9 \\
\hline 160 & 9.825 & 1780.1 \\
\hline 180 & 8.987 & 1882.5 \\
\hline 190 & 8.743 & 1924.6 \\
\hline 200 & 8.375 & 1895 \\
\hline 210 & 8.013 & 1680.8 \\
\hline 220 & 6.435 & 1245.6 \\
\hline 225 & 3.015 & 795.4 \\
\hline 230 & 0.331 & 170 \\
\hline
\end{tabular}


Table 3 MPP tracked for dynamic insolation

\begin{tabular}{|c|c|c|c|}
\hline Insolation $_{(\mathbf{W}} \mathbf{m}^{\mathbf{2}} \mathbf{)}$ & $\mathbf{I}_{\mathbf{m}}(\mathbf{A})$ & $\mathbf{V}_{\mathbf{m}}(\mathbf{V})$ & $\mathbf{M P P}(\mathbf{W})$ \\
\hline 100 & 1.394 & 148.3 & 105.47 \\
\hline 200 & 2.687 & 162.5 & 265.53 \\
\hline 300 & 3.254 & 172.5 & 458.46 \\
\hline 400 & 4.782 & 178.7 & 676.51 \\
\hline 500 & 5.240 & 182.1 & 837.43 \\
\hline 600 & 6.689 & 184.9 & 1086.24 \\
\hline 700 & 7.147 & 186.8 & 1315.75 \\
\hline 800 & 9.517 & 189.3 & 1513.41 \\
\hline 900 & 10.836 & 190.3 & 1716.92 \\
\hline 1000 & 11.124 & 191.7 & 1908.53 \\
\hline
\end{tabular}

Similarly, the effectiveness of MB algorithm is experimentally verified for dynamically tracking MPP for the typical case of shading. The proposed scheme is found to be equally effective for tracking under dynamically varying shading as well. Table 4 summarizes the results for shading where current also varies significantly and even becomes negative for fully shaded panels because of reverse saturation.

Table 4 MPP tracked for dynamic partial shading

\begin{tabular}{|c|c|c|c|}
\hline Shading $(\boldsymbol{\%})$ & $\mathbf{M P P}(\mathbf{W})$ & $\mathbf{V}_{\mathbf{m}}(\mathbf{V})$ & $\mathbf{I}_{\mathbf{m}}(\mathbf{A})$ \\
\hline 0 & 1923.96 & 229.89 & 11.18 \\
\hline 10 & 1731.61 & 229.35 & 10.03 \\
\hline 20 & 1517.12 & 225.16 & 9.15 \\
\hline 30 & 1304.23 & 221.87 & 7.97 \\
\hline 40 & 1093.78 & 213.02 & 6.83 \\
\hline 50 & 885.75 & 216.29 & 5.69 \\
\hline 60 & 680.47 & 211.34 & 4.55 \\
\hline 70 & 479.57 & 204.13 & 3.41 \\
\hline 80 & 285.45 & 189.5 & 2.27 \\
\hline 90 & 97.72 & 123.29 & 1.13 \\
\hline 100 & 0.29 & 0 & -0.17 \\
\hline
\end{tabular}

Finally for validation of effectiveness of proposed MB algorithm the tracked maximum power measured by experimental work and predicted by simulation work are plotted and compared. First the comparison of power output characteristics obtained at STC is shown in the Figure 13. It is found that MB algorithm is not only capable of tracking MPP in dynamic conditions but at the same time it also gives out a high tracking efficiency. Then the comparative result of MPP tracked for dynamic variations in the insolation has been plotted in Figure 14 and finally results are compared and plotted for the most typical i.e partial shading case in Figure 15. 


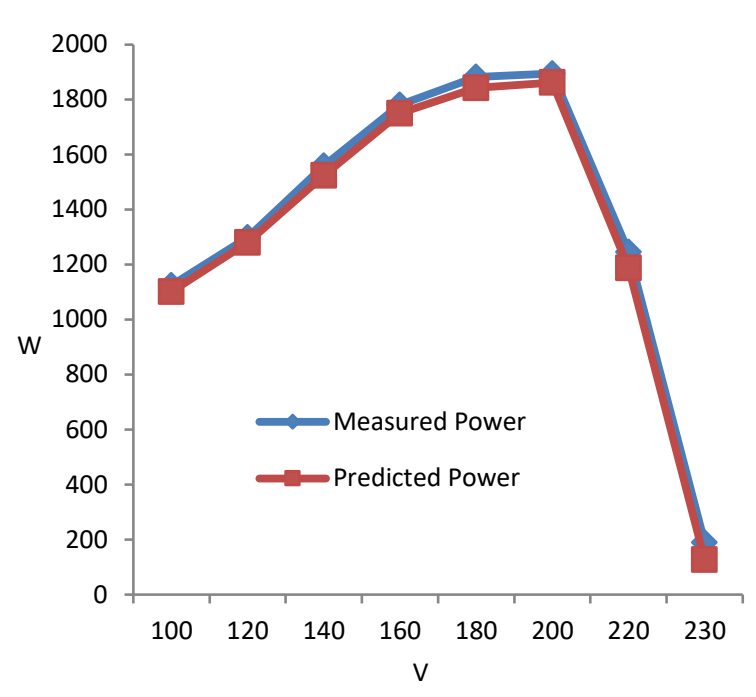

Figure $13 \mathrm{PV}$ power output tracked at STC

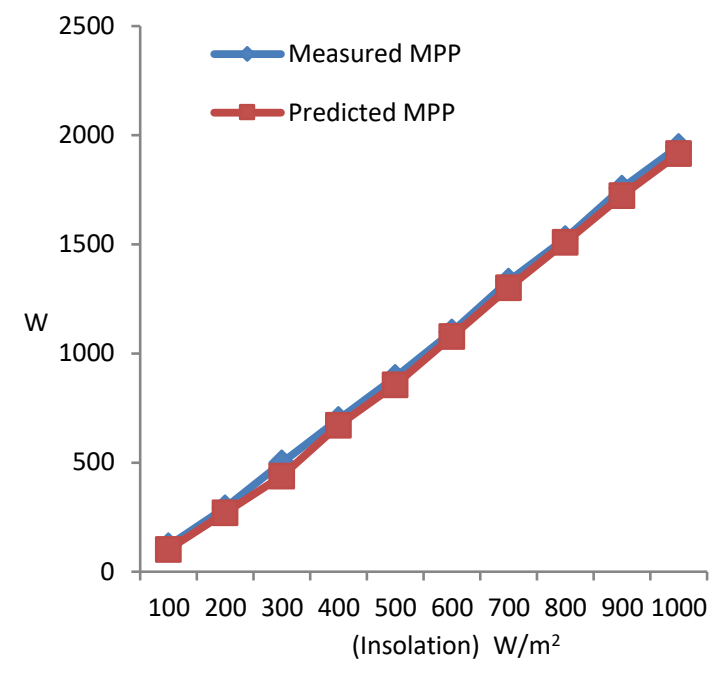

Figure 14 MPP tracked for dynamic insolation

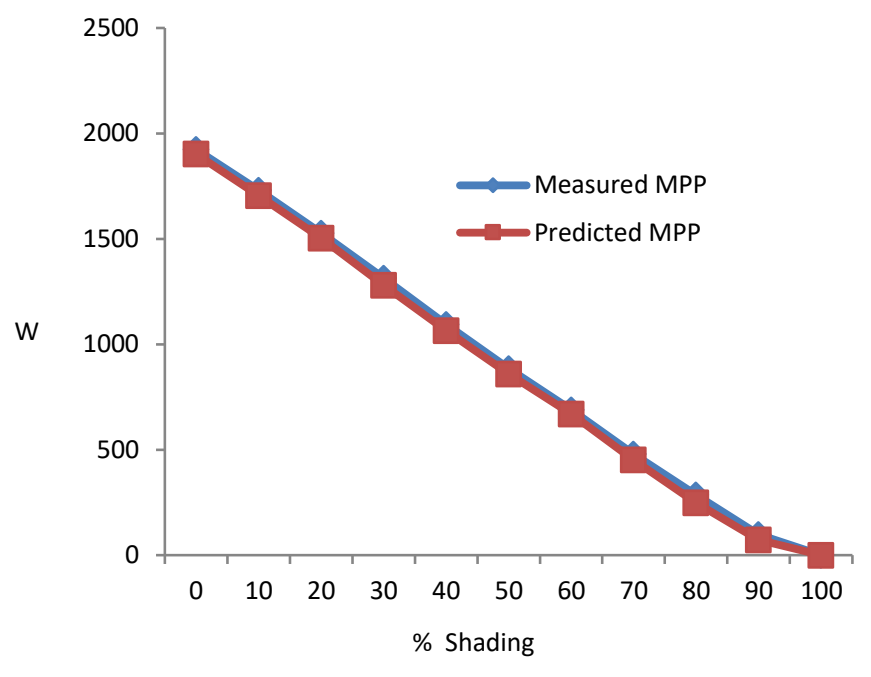

Figure 15 MPP tracked for dynamic shading

\section{CONCLUSION}

There are several challenges being faced as photovoltaic power penetrates deep into the distribution system. One of the major tasks is to restrict the operation of PV panels at MPP irrespective of environmental variations and hence it requires effective and efficient tracking algorithm. This work has presented an enhanced model based MPPT algorithm which is found to be very effective under dynamic conditions. Here, accurate modeling of PV panel combined with precised estimation of parameters have given a distinct feature to proposed MB algorithm and thus provided a comprehensive solution to overcome the limitations of earlier techniques. A detailed performance analysis has been carried out to signify the effectiveness of $\mathrm{MB}$ algorithm. Simulated results have been obtained which are then investigated experimentally by tracking the real time values. Finally both the results are compared and found to be matching closely. Thus it has been verified that MB algorithm is very efficient and effective for tracking not only in dynamically varying insolation or temperature but additionally it is equally capable for typical shaded panels also. 
Introducing Dynamic Feature in Maximum Power Point Tracking Algorithm for PV System

\section{REFERENCES}

[1] S. Sidharthan and P. Mathiazagan, Performance Study on Solar PV System, International Journal of Electrical Engineering and Technology (IJEET), 12(4), 2021, pp. 99-104.

[2] U. Prasad, S. Rajwar and R. Devarapalli, Simulation and Analysis on Photovoltaic Solar Power System, International Journal of Electrical Engineering and Technology (IJEET), 11(6), 2020, pp. 34-41.

[3] R. K. Pachauri, I. Kansal, T. S. Babu and H. H. Alhelou, Power Losses Reduction of Solar PV Systems Under Partial Shading Conditions Using Re-Allocation of PV Module-Fixed Electrical Connections, IEEE Access, 9, 2021, 94789-94812.

[4] N. Dahate and N. R. Bhasme, Review on MPPT Techniques used in PV System, International Journal of Electrical Engineering and Technology (IJEET), 10(4), 2019, pp. 22-30.

[5] M. Aquib, S. Jain and V. Agarwal, A Time-Based Global Maximum Power Point Tracking Technique for PV System, IEEE Transactions on Power Electronics, 35(1), 2020, pp. 393-402.

[6] D. Verma, S. Nema, and S. K. Dash, "MPPT techniques: Recapitulation in solar PV systems," Renewable Sustainable Energy Review, 54, 2016, pp. 1018-1034.

[7] D. Quan, M. Mao, P. Duan, and B. Hu, An intelligent algorithm for MPPT in PV system under partial shading conditions, IEEE Transactions on Instrument Measurement Control, 39(2), 2017, pp. 244-256.

[8] S. K. Kollimalla and M. K. Mishra, A novel adaptive P\&O MPPT algorithm considering sudden changes in the irradiance, IEEE Transactions on Energy Conversion, 29(3), 2014, pp. 602-610.

[9] K.S. Tey, S. Mekhilef, Modified Incremental Conductance Algorithm for Photovoltaic System Under Partial Shading Conditions and Load Variation, IEEE Transactions on Industrial Electronics, 61(10), 2014, pp. 5384-5392.

[10] Jubaer Ahmed and Zainal Salam, An Enhanced Adaptive P\&O MPPT for Fast and Efficient Tracking Under Varying Environmental Conditions, IEEE Transactions on Sustainable Energy, 9(3), 2018, pp. 1487-1496.

[11] D. C. Huynh and M. W. Dunnigan, Development and Comparison of an Improved Incremental Conductance Algorithm for Tracking the MPP of a Solar PV Panel, IEEE Transactions on Sustainable Energy, 7(4), 2016,1421-1429.

[12] T. H. Kawan and X. Wu, MPPT using a variable antecedent fuzzy logic control, Solar Energy, 137, 2016, pp. 189-200.

[13] M. N. Ali, "Improved Design of Artificial Neural Network for MPPT of Grid-Connected PV Systems," Proc. IEEE Int. Conf. MEPCON, Cairo, Egypt, 2018, pp. 1-6.

[14] C. Lee, H. Tsou, T. Chou and K. Weng, Application of the hybrid taguchi genetic algorithm to maximum power point tracking of photovoltaic system, Proc IEEE Int. Conf. ICASI, Chiba, Japan, 2018.

[15] H. Li, D. Yang, W. Su, J. Lu and X. Yu, An Overall Distribution Particle Swarm Optimization MPPT Algorithm for Photovoltaic System Under Partial Shading, 66(1), 2019, pp. 265-275. 
[16] J. A. Nemours and S. Choudhary, "Performance Analysis of Fuzzy Logic Maximum Power Point Tracking Scheme for Solar PV System Under Varying Load and Atmospheric Conditions,” Proc. IEEE Int. Conf. IEEE PES/ IAS Power-Africa, 2019, pp. 134-139.

[17] K. Bataineh, Improved hybrid algorithms-based MPPT algorithm for PV system operating under severe weather conditions, IET Power Electronics, 12(4), 2019, pp. 703-711.

[18] H. Rezk, M. Aly, M. Al-Dhaifallah and M. Shoyama, Design and Hardware Implementation of New Adaptive Fuzzy Logic-Based MPPT Control Method for Photovoltaic Applications, Journal Article, IEEE Access, 7, 2019, pp. 106427-106438.

[19] M. Kermadi, Z. Salam, J. Ahmed and El. M. Berkouk, An Effective Hybrid Maximum Power Point Tracker of Photovoltaic Arrays for Complex Partial Shading Conditions, 66(9), 2019, pp. 6990-7000.

[20] M. A. Koondhar, M. I. Jamali, A. S. Channa and I. A. Laghari, Partial Shading Effect on the Performance of PV Panel and its Different Circuit Topologies Based Mitigation Techniques: A Review, International Journal of Advanced Research in Engineering and Technology (IJARET), 12(4), 2021, pp. 15-23.

[21] B. C. Babu and S. Gurjar, A novel simplified two-diode model of photovoltaic module, IEEE Journal of Photovoltaics, 4(4), 2014, pp. 1156-1161.

[22] H. K. Mehta, H. Warke, K. Kukadia and A. K. Panchal, "Accurate Expressions for Single Diode Model Solar Cell Parameterization, IEEE Journal of Photovoltaics, 9(3), 2019, pp. 803-810. 